\title{
POTENCIAL DE TRANSFERÊNCIA DE SEDIMENTOS DAS BACIAS CONTRIBUINTES DO SISTEMA CÁRSTICO TERRA RONCA
}

\author{
POTENTIAL OF SEDIMENT TRANSFER OF CONTRIBUTING \\ BASINS OF TERRA RONCA KARSTIC SYSTEM
}

\author{
POTENTIEL DE TRANSFERT DES SEDIMENTS DE LES BASSINS \\ CONTRIBUTEURS DU SYSTÉME KARSTIQUE TERRA RONCA
}
Ana Caroline da Silva Faquim - Universidade Federal de Goiás - Goiânia - Goiás - Brasil anacarolinefaquim@gmail.com
Márcio Henrique de Campos Zancopé - Universidade Federal de Goiás - Goiânia - Goiás - Brasil zancope@ufg.br
Luis Felipe Soares Cherem - Universidade Federal de Goiás - Goiânia - Goiás - Brasil luis.cherem@gmail.com

\section{Resumo}

0 Índice de Potencial de Transferência de Sedimentos (PTS) estima a capacidade da rede de drenagem transportar sua carga sedimentar. Este trabalho calcula e compara o PTS de bacias de $2^{\mathrm{a}}, 3^{\mathrm{a}}$ e $4^{\mathrm{a}}$ ordem hierárquica, cujos canais drenam e proveem sedimentos para dentro das cavernas do Parque Estadual Terra Ronca (PETeR), no nordeste de Goiás. Identificaram-se 438 bacias de $2^{\mathrm{a}}$ ordem com baixo valor de PTS em um total de 863 bacias, 83 bacias de $3^{\text {a }}$ ordem de valor médio em um total de 194 bacias e 16 bacias de $4^{\mathrm{a}}$ ordem com valor médio em um total de 37 bacias de hierárquica. As bacias hidrográficas da área têm capacidade moderada a baixa de lançar sedimentos nas cavernas do PETeR.

Palavras-chave: Parâmetros morfométricos, rede de drenagem, geomorfologia fluvial.

\section{Abstract}

The potential of sediment transfer (PTS) index estimates the capacity of the drainage network to transport its sedimentary load. This paper calculates and compares the PTS of the basins of 2nd, 3rd e 4th hierarchical order, which channels drain into and provides sediments to the caves of the State Park Terra Ronca (PETeR), in the northeast of Goiás. It has been identified 438 basins of 2 nd order with low PTS value out of a total of 863; 83 basins of 3 rd order with moderate value out of 194 , and 16 basins of 4 th order out of 37 . The basins of the study area showed moderate to low capacity to supply sedimentary load to caves of the PETeR.

Key words: Morphometric parameters, drainage network, fluvial geomorphology.

\section{Résumé}

L'indice du Potentiel de Transfert des Sédiments (PTS) estime la capacité de transport sedimentaire dans les bassin versants. Cette étude calcule et compare le PTS des bassins de $2 \mathrm{e}, 3 \mathrm{e}$ et $4 \mathrm{e}$ ordre hiérarchique fluvial, dont les fleuves drainent et fournissant des sédiments vers les les grottes du Parque Estadual de Terra Ronca (PETeR), dans le nord-est de Goias. Le resultats montrent que il y a 438 bassin de 2e ordre à faible valeurs de PTS entre un total de 863 bassins; 83 bassins de 3e ordre des moyennes valeur entre un total de 194 bassins ; et 16 bassins de $4 \mathrm{e}$ ordre des moyennes valeur entre un total de 37 bassins. Les bassin versants de la region ont une capabilité modérée à faible de fournir des sediments vers les grottes du PETeR. Mots-clés: Morphométriques paramètres, bassin versants, géomorphologie fluviale. 
Introdução

Estudos científicos sobre drenagens fluviais têm grande influência para o entendimento da dinâmica das paisagens. Segundo Christofoletti (1980), a análise da rede hidrográfica leva à compreensão de numerosas questões geomorfológicas, pois no interior dos rios encontram-se os processos mais ativos na esculturação da paisagem terrestre.

As redes fluviais têm o trabalho de transportar a carga hídrica e sedimentar das bacias hidrográficas e, devido às características geográficas, algumas apresentam maior capacidade de transporte de água e sedimentos que outras (Latrubesse; Carvalho, 2006). Uma das análises que possibilitam entender o comportamento hidrológico e sedimentar em bacias hidrográficas, destacadamente ao longo da drenagem, é feita com a aplicação de parâmetros morfométricos (Meliani, 2006). A integração desses parâmetros permite entender a diversidade ambiental associada a características morfométricas entre bacias hidrográficas, ao exemplo da capacidade de transporte de sedimento (Zancopé; Bayer, 2012).

Estudos dessa natureza são indispensáveis ao planejamento territorial de bacias hidrográficas por subsidiarem a proposição de diretrizes do uso e ocupação do solo e de recursos hídricos. Especificamente no que diz respeito ao planejamento dos recursos hídricos, entender a dinâmica de transporte de sedimentos pelos canais fluviais tem papel central por fornecer subsídios de mitigação ao assoreamento de canais e também de reservatórios de água. A esses estudos, soma-se, geralmente, o mapeamento dos depósitos associados ao assoreamento (Zancopé; Goncalves; Bayer, 2015).

Nesse contexto, inserem-se também os canais fluviais que tem parte de seu curso em ambientes cavernícolas, cujos depósitos não podem ser mapeados por sensoriamento remoto, como o exemplo do relevo cárstico do leste do Vão do Paranã, em Goiás (Latrubesse; Carvalho, 2006), onde está inserido o Parque Estadual de Terra Ronca, com sete das trinta maiores cavernas do Brasil (Mateucci; Soares Filho; Nascimento, 2001).

Os sistemas de cavernas do PETeR recebem a descarga líquida e sedimentar da Serra Geral de Goiás, sob intensa ação morfodinâmica (Zancopé; Momoli; Bayer, 2013), pelos rios que nascem na Serra Geral e atravessam o carste do PETeR, transportando os sedimentos lá produzidos até os sumidouros nas cavernas do Parque. A injeção de sedimentos nos sumidouros do PETeR pode levar a obstrução parcial ou total das cavernas, 
similarmente demonstrado por Laureano, et al. (2016), dependendo do volume de sedimentos transportados pela rede de drenagem a montante. Nesses termos, descobrir quais bacias hidrográficas apresentam maior capacidade de injetar maior volume de sedimentos nas cavernas torna-se importante para a melhor gestão do PETeR e da área de amortecimento do entorno.

Dessa forma, este trabalho apresenta uma avaliação do Potencial de Transferência de Sedimentos (PTS) das bacias hidrográficas que aportam sedimentos ao Sistema Cárstico Terra Ronca, sendo calculado e analisado esse índice para as bacias dos rios São Domingos, São Vicente e São Mateus, as quais atravessam o PETeR, e, simultaneamente, suas cavernas que funcionam como exutório das bacias contribuintes quanto à potencialidade do aporte sedimentar.

\section{Materiais e Método}

\section{Área de Estudo}

A área de estudo está localizada no município de São Domingos, no nordeste do estado de Goiás, exclusivamente compreendendo as bacias hidrográficas do médio e alto curso dos rios São Domingos, São Vicente e São Mateus, nas quais está inserido o Parque Estadual Terra Ronca (PETeR). Tal escolha justifica-se pelas sub-bacias do médio e alto curso dos referidos rios estarem a montante do sistema cárstico, contribuindo potencialmente com sedimentos às cavernas do PETeR.

Esta área se destaca por apresentar, a leste, as escarpas da Serra Geral de Goiás, no limite interestadual Goiás-Bahia. No topo da Serra, estão os Chapadões do Oeste da Bahia, sustentados pelos arenitos do Grupo Urucuia, os quais se constituem como aquíferos que servem às nascentes dos rios goianos (CPRM, 2012). Os rios que nascem na escarpa da Serra Geral drenam para o oeste, constituindo os afluentes da margem direita do Rio Paranã. O alto curso desses rios passam por patamares aplainados embutidos no sopé da Serra Geral, sustentados por coberturas detríticas arenosas tércio-quaternárias, até alcançarem os afloramentos de calcários do Grupo Bambuí (Brasil, 1982). Antes de alcançarem o Rio Paranã, ao atravessarem as rochas do Grupo Bambuí, esses rios desenvolvem trechos subterrâneos, contribuindo para a espeleogênese do Sistema Cárstico Terra Ronca e formas de relevo caracterizadas pela dissolução química 
de rochas que favorece a formação de cavernas, galerias subterrâneas com espeleotemas diversos, dolinas, mogotes etc (Latrubesse; Carvalho, 2006).

Localização da área de estudo
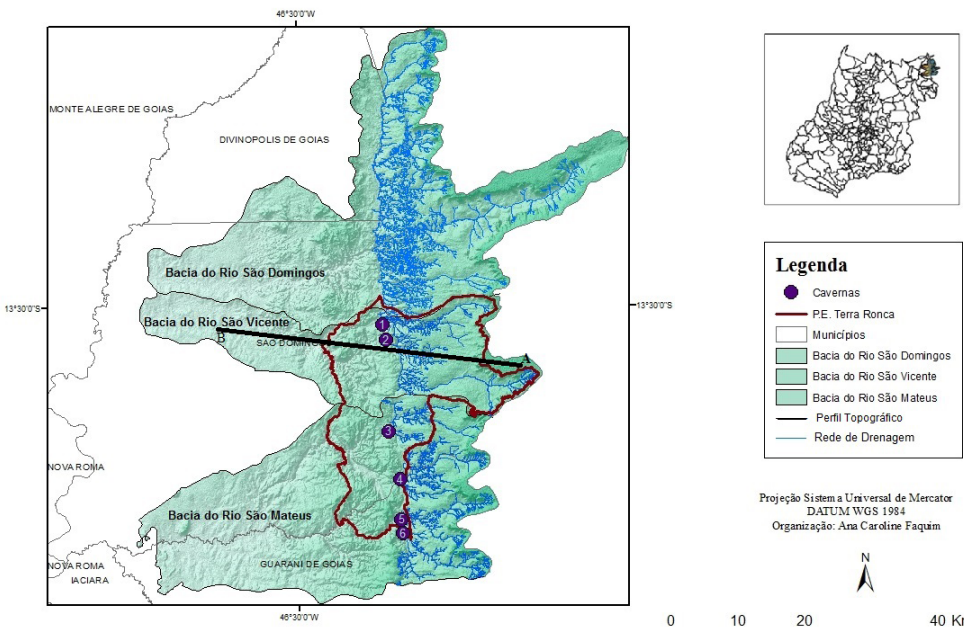

Projeção Si stema Universal de Mercator

Organizaçã̃o: Ana Car oline $\mathrm{F}$

$\stackrel{N}{\Lambda}$

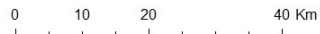

$\mathrm{B}$

A

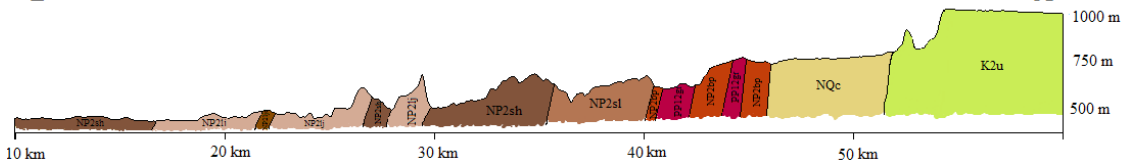

\begin{tabular}{|c|c|c|}
\hline Cenozóico & NQc - Depósitos colúvio-eluviais & $\begin{array}{l}\text { Depósitos de areia, depósitos de cascalho, depósitos } \\
\text { de argila, laterita. }\end{array}$ \\
\hline Mesozóico & K2U - Grupo Urucuia & $\begin{array}{l}\text { Conglomerado, Arenito conglomerático, Pelítico, } \\
\text { Arenito. }\end{array}$ \\
\hline \multirow{6}{*}{ 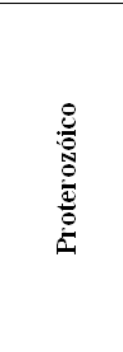 } & $\begin{array}{l}\text { NP2ljc - Grupo Bambuí - Formação } \\
\text { Lagoa do Jacaré - Fáceis Calcário }\end{array}$ & Calcário, intercalações de siltitos e margas. \\
\hline & $\begin{array}{l}\text { NP2lj - Grupo Bambuí - Formação } \\
\text { Lagoa do Jacaré }\end{array}$ & $\begin{array}{l}\text { Intercalações cíclicas de siltitos e margas com lentes } \\
\text { e/ou camadas de calcários pretos. }\end{array}$ \\
\hline & $\begin{array}{l}\text { NP2sh - Grupo Bambuí - Subgrupo } \\
\text { Paraopeba - Formação Serra de Santa } \\
\text { Helena }\end{array}$ & $\begin{array}{l}\text { Folhelhos e siltitos com intercalações de arenitos } \\
\text { finos e calcários. }\end{array}$ \\
\hline & $\begin{array}{l}\text { NP2sl - Grupo Bambuí - Subgrupo } \\
\text { Paraopeba - Formação Sete Lagoas }\end{array}$ & $\begin{array}{l}\text { Pelitos e margas, com intercalações de lentes de } \\
\text { calcários e dolomitos com estruturas estromatolíticas. }\end{array}$ \\
\hline & $\begin{array}{l}\text { NP2bp - Grupo Bambuí - Subgrupo } \\
\text { Paraopeba }\end{array}$ & $\begin{array}{l}\text { Calcarenito, arcóseo, dolomito, siltito, folhelho, } \\
\text { argilito, rocha pelítica ritímica, marga. }\end{array}$ \\
\hline & $\begin{array}{l}\text { PP12gr-Complexo Almas- } \\
\text { Cavalcante-Unidade Ortognáissica }\end{array}$ & $\begin{array}{l}\text { Granito, tonalito, trondhjemito, Quartzo diorito, } \\
\text { Quartzo monzodiorito, granodiorito. }\end{array}$ \\
\hline
\end{tabular}

Figura 1- Localização da área de estudo

Fonte: GOIÁS (Estado); SIEG - Sistema Estadual de Geoinformação. Disponível em: <http://www2.sieg.go.gov.br/> Acesso em: 18 nov. 2016.. 


\section{Procedimentos Metodológicos}

O Potencial de Transferência de Sedimentos (PTS) estima a capacidade relativa da rede de drenagem em transferir os sedimentos fornecidos pelas vertentes ou obtidos nas margens ou fundo dos leitos. Uma sub-bacia, cuja rede de drenagem possui baixo PTS, tem capacidade baixa de transporte, ou seja, está suscetível a depositar os sedimentos ao longo dos rios, produzindo assoreamento. Por outro lado, as sub-bacias cuja rede possui PTS elevado têm capacidade acentuada de fornecer sua carga sedimentar aos rios à jusante.

A classificação do PTS foi determinada pela associação dos parâmetros morfométricos da rede de drenagem para sub-bacias de $2^{\mathrm{a}}$, $3^{\mathrm{a}}$ e $4^{\mathrm{a}}$ ordens hierárquicas da área de estudo. Conforme Christofoletti (1980) e Zancopé e Bayer (2012), a associação de parâmetros morfométricos somente deve ser efetuada entre bacias de mesma ordem hierárquica. A escolha das respectivas ordens hierárquicas deveu-se ao menor número de sub-bacias avaliadas que pudesse atender um maior recobrimento da área de estudo. Os parâmetros morfométricos analisados foram Densidade Hidrográfica (Dh); Densidade de Drenagem (Dd); Extensão do Percurso Superficial (Eps); e Gradiente Fluvial (Gd) para os rios que constituem os eixos principais das sub-bacias. Os parâmetros foram calculados de acordo com Christofoletti (1980).

Para o cálculo e classificação dos parâmetros morfométricos da rede de drenagem foram vetorizados os canais a partir de imagens satélites. Os Modelos Digitais de Elevação (MDE), elaborados com as imagens SRTM (resolução 30 metros), disponibilizadas pela NASA-EUA, permitiram obter os dados altimétricos. As imagens foram georreferenciadas em DATUM WGS 1984 em Sistema de Coordenadas UTM, zona 23S. Também foram interpretadas fotos aéreas verticais (escala 1:10.000), disponibilizadas pela Secretaria do Meio Ambiente e Recursos Hídrico do Governo do Estado de Goiás.

Uma vez restituída, a rede de drenagem foi hierarquizada de acordo com Strahler (1952). Os dados e variáveis foram processados no software ERSI@ArcGis 10.2, permitindo a determinação das variáveis para cálculo dos parâmetros. Os valores dos parâmetros morfométricos para cada subbacia foram classificados em 5 categorias (muito alto, alto, médio, baixo e muito baixo), seguindo a determinação automática pelo método Algoritmo de Jenks (quebras naturais) no ArcGis. 
Os parâmetros foram associados dois a dois, seguindo três etapas (Figura 2): na etapa 1, associou-se os parâmetros Dh e Dd, determinando-se um potencial parcial (parcial 1); na etapa 2, o potencial parcial 1 associou-se ao $\mathrm{Gd}$, produzindo o potencial parcial 2; na etapa 3, associou-se o potencial parcial 2 ao Eps, determinando o Potencial de Transferência de Sedimentos final.

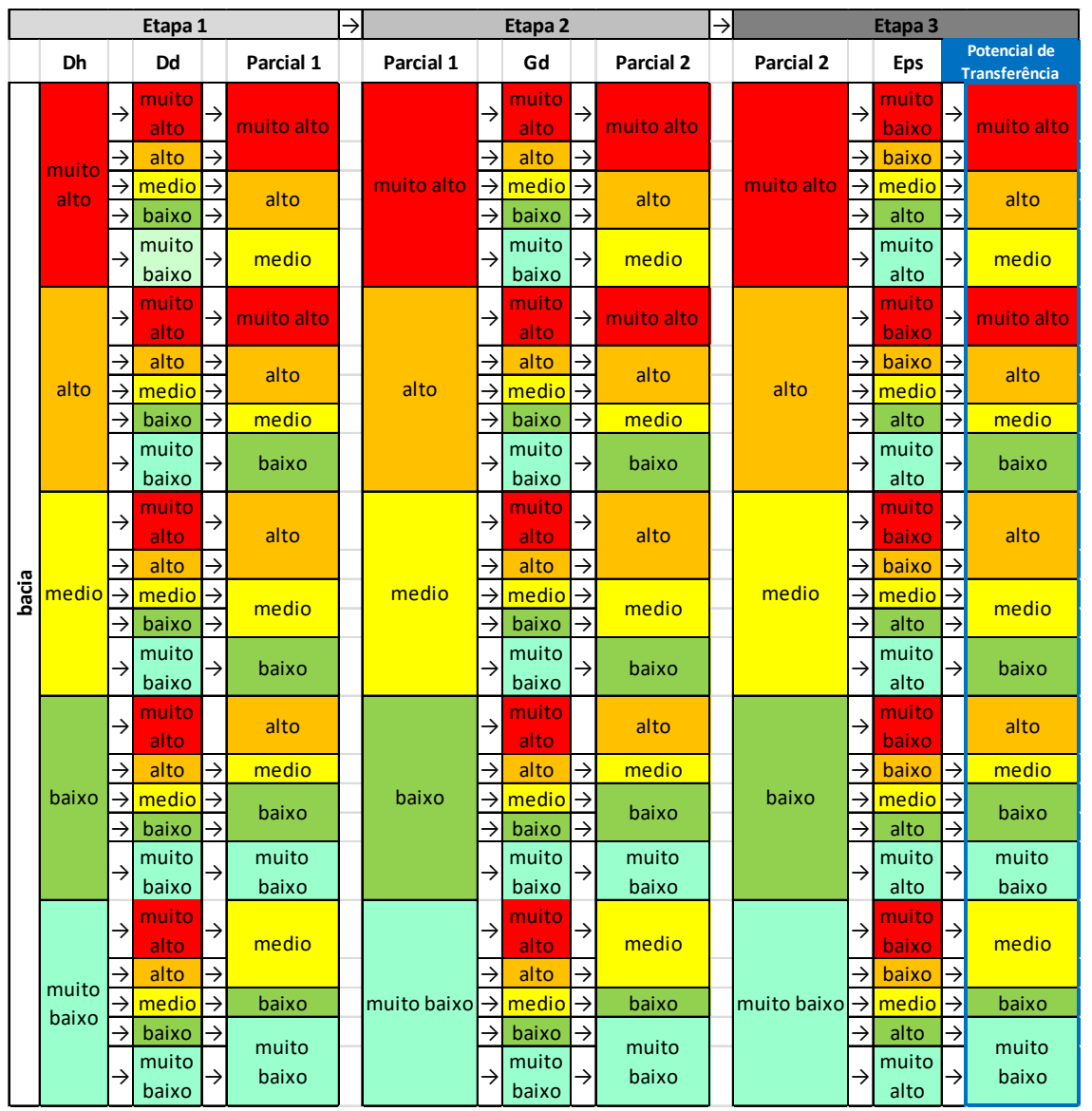

Figura 2 - Etapas da associação dos parâmetros morfométricos da rede de drenagem para cada sub-bacia de mesma ordem hierárquica 


\section{Resultados e discussões}

A produção dos dados e aplicação dos procedimentos metodológicos permitiu a avaliação do Potencial de Transferência de Sedimentos (PTS) das sub-bacias de $2^{\mathrm{a}}, 3^{\mathrm{a}}$ e $4^{\mathrm{a}}$ ordem hierárquica que são contribuintes do Sistema Cárstico Terra Ronca. Foram identificadas 863 sub-bacias de $2^{\text {a }}$ ordem, alcançando uma área de 294,75 km², 194 sub-bacias de $3^{\text {a }}$ ordem, área de $562,54 \mathrm{~km}^{2}$ e 37 de $4^{\mathrm{a}}$ ordem hierárquica alcançando uma área total de $872,03 \mathrm{~km}^{2}$.

\section{PTS das sub-bacias de $2^{\mathrm{a}}$ ordem}

Avaliando os resultados obtidos, há o predomínio de sub-bacias com potencial baixo de transferência de sedimentos para as sub-bacias classificadas como de $2^{\mathrm{a}}$ ordem hierárquica. Devido às sub-bacias de $2^{\circ}$ ordem hierárquica estarem dispostas predominantemente sobre regiões onde o relevo se apresenta mais aplainado, os valores de Gd dessas subbacias são menores. Com isso, a associação entre os demais parâmetros morfométricos, conforme a metodologia (Figura 2) produz essa tendência de PTS baixos.

A Tabela 1 mostra a quantidade de sub-bacias e sua área correspondente para as três bacias hidrográficas da área de estudo quanto ao Potencial de Transferência de Sedimentos. Ao analisar a Figura 3, é possível perceber que a Bacia do Rio São Domingos tem maior influência no sistema por apresentar maior abrangência e maior número de sub-bacias.

Tabela 1 - Quantidade de sub-bacias e área (em km2) quanto ao PTS, 2ª ordem

\begin{tabular}{ccccccc}
\hline & Muito Alto & Alto & Médio & Baixo & $\begin{array}{c}\text { Muito } \\
\text { Baixo }\end{array}$ & Total \\
\hline \multicolumn{1}{c}{ Bacias } & Quant./Área & Quant./Área & Quant./Área & Quant./Área & Quant./Área & Quant./Área \\
\hline S. Domingos & 0 & $6 / 2,95$ & $221 / 62,38$ & $258 / 85,11$ & $65 / 15,69$ & $550 / 116,14$ \\
\hline São Vicente & 0 & $1 / 0,43$ & $40 / 14,35$ & $55 / 27,38$ & $13 / 19,11$ & $109 / 61,28$ \\
\hline São Mateus & 0 & $1 / 1,47$ & $35 / 34,93$ & $125 / 50,80$ & $43 / 30,11$ & $204 / 117,33$ \\
\hline & & & & & Total & $863 / 267,75$ \\
\hline
\end{tabular}


PTS das Bacias dos Rios São Domingos, São Vicente e São Mateus, $2^{\circ}$ ordem

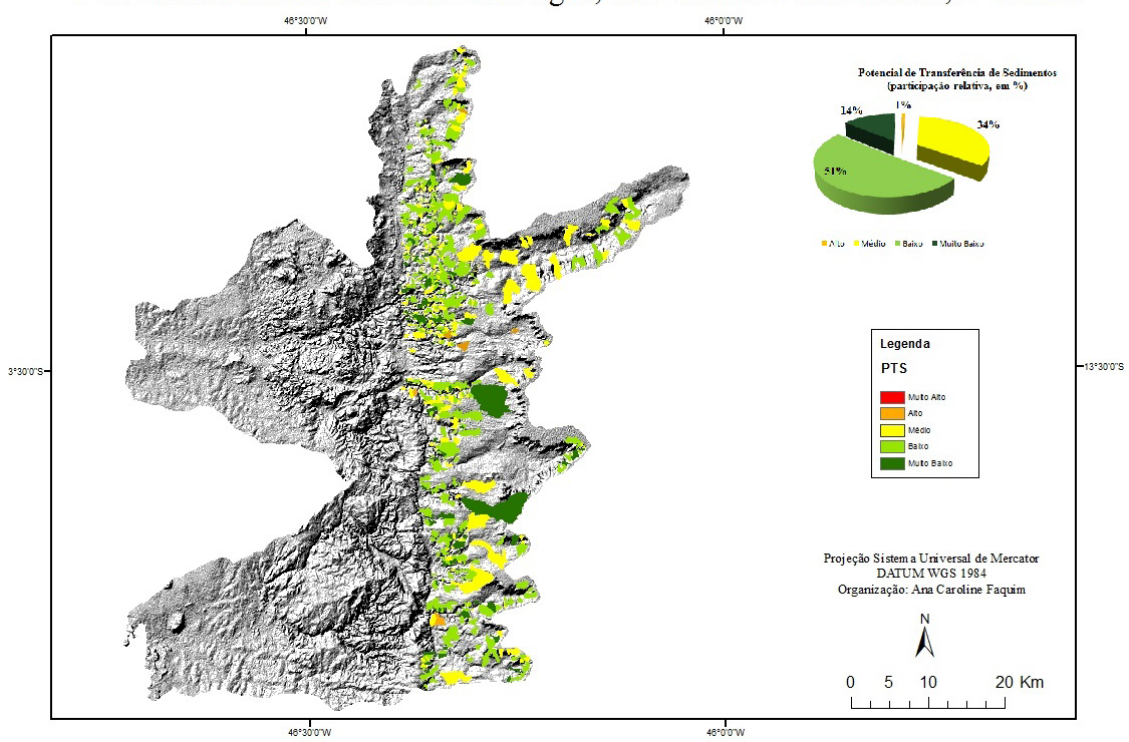

Figura 3 - PTS das Bacias dos Rios São Domingos, São Vicente e São Mateus, $2^{\circ}$ ordem Fonte: SIEG (2016).

PTS das sub-bacias de $3^{\text {a }}$ ordem

Os resultados demonstraram o predomínio de sub-bacias com Potencial de Transferência de Sedimentos moderado a elevado para a $3^{a}$ ordem hierárquica. Destaca-se que $8 \%$ das sub-bacias apresentaram potencial muito alto, $40 \%$ das sub-bacias apresentaram potencial alto, 43\% apresentaram um potencial médio, $8 \%$ apresentaram um potencial baixo e somente $1 \%$ das sub-bacias apresentou potencial muito baixo.

Percebe-se que, em área, as sub-bacias com Potencial de Transferência de Sedimentos (PTS) baixo são maiores que as com PTS alto. Isso ocorre, pois, as sub-bacias com PTS baixo localizam-se num setor mais aplainado da área de estudo (Figura 4), entre o sopé da Serra Geral de Goiás (leste da área) e os terrenos cársticos (oeste da área). Nessa porção intermediária aplainada, as sub-bacias apresentaram área maior 
que, na somatória de área, superam as sub-bacias com PTS mais elevado. Por outro lado, os gradientes dos rios principais das sub-bacias nessa porção aplainada são mais baixos, que aliado à área maior, influenciam para baixo os PTS, uma vez que essas variáveis são usadas para determinar o PTS da cada sub-bacia. Correlações entre as variáveis morfométricas, posição na compartimentação da paisagem e litologia serão investigadas em estudos futuros.

A Tabela 2 a seguir mostra a quantidade de sub-bacias de $3^{\text {a }}$ ordem e sua área correspondente para as três bacias hidrográficas da área de estudo quanto ao Potencial de Transferência de Sedimentos.

Tabela 2 - Quantidade de sub-bacias e área (em $\left.\mathrm{km}^{2}\right)$ quanto ao PTS, $3^{\mathrm{a}}$ ordem

\begin{tabular}{ccccccc}
\hline & Muito Alto & Alto & Médio & Baixo & Muito Baixo & Total \\
\hline Bacias & Quant./Área & Quant./Área & Quant./Área & Quant./Área & Quant./Área & Quant./Área \\
\hline S. Domingos & $13 / 2,47$ & $61 / 40,12$ & $49 / 130,44$ & $8 / 78,90$ & $1 / 12,83$ & $132 / 264,31$ \\
\hline São Vicente & 0 & $6 / 5,52$ & $16 / 29,91$ & $3 / 62,12$ & 0 & $25 / 97,57$ \\
\hline São Mateus & $2 / 0,82$ & $11 / 6,37$ & $18 / 97,43$ & $5 / 62,96$ & $1 / 32,95$ & $37 / 200,56$ \\
\hline & & & & Total & $194 / 562,54$ \\
\hline
\end{tabular}

Fonte: Elaborada pelos autores (2016).

O desempenho geral da quantidade maior de sub-bacias com PTS médio a alto para toda área estudada também é verificado em particular para cada bacia hidrográfica investigada: São Domingos, São Vicente e São Mateus. Destaca-se a bacia do São Domingos que apresentou número maior de sub-bacias com PTS alto em relação às demais. Essa diferença provavelmente se deve às variáveis para determinação dos parâmetros morfométricos como área das sub-bacias e gradiente dos rios principais.

A distribuição dessas variáveis na área de estudo influencia a localização das sub-bacias de PTS mais elevados nas bacias do São Domingos e do São Vicente, cuja maior frequência ocorre mais próxima dos terrenos com afloramentos das rochas do Grupo Bambuí e do sistema cárstico. Essa distribuição entre os PTS mais elevados não ocorre para a bacia do São Mateus.

O gradiente dos rios principais parece ser uma variável importante na determinação dos PTS para a área de estudo, visto que as sub-bacias com PTS mais elevado também ocorrem junto a escarpa da Serra Geral 
de Goiás. A correlação entre as variáveis morfométricas (gradiente, área de bacia, quantidade de canais etc.) deve ser investigada noutro momento, uma vez que não constitui o objetivo deste trabalho.

PTS das Bacias dos Rios São Domingos, São Vicente e São Mateus, $3^{\circ}$ ordem

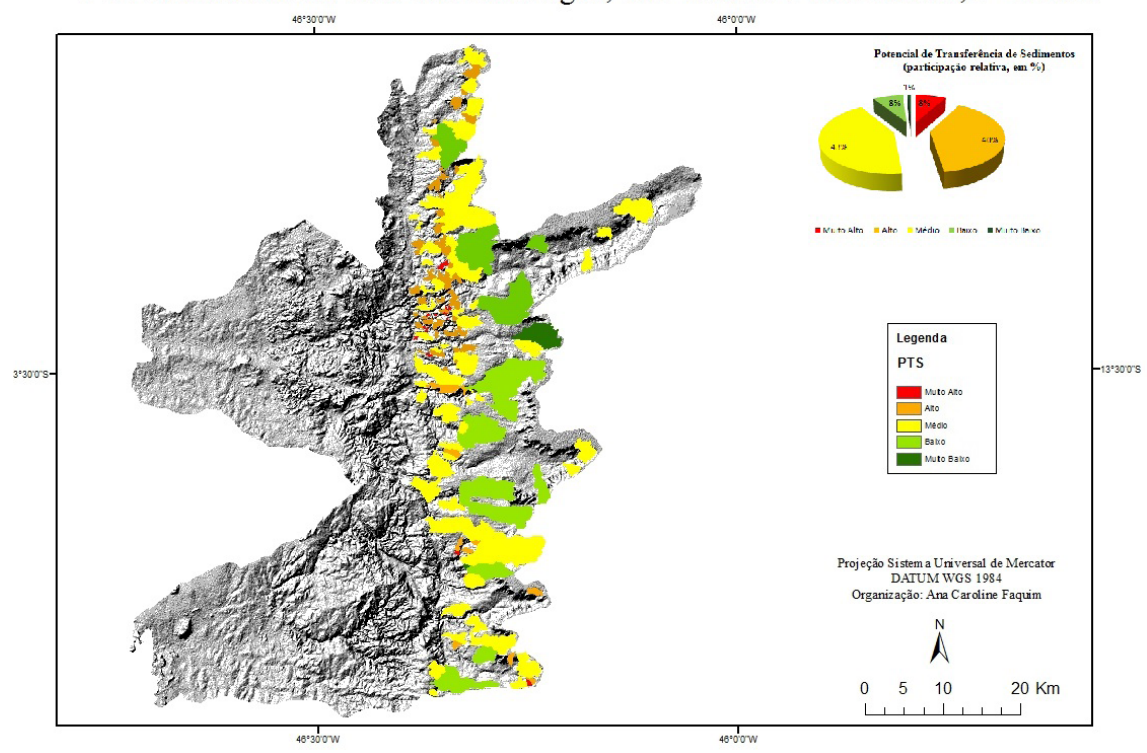

Figura 4 - PTS das Bacias dos Rios São Domingos, São Vicente e São Mateus, $3^{\circ}$ ordem

Fonte: SIEG (2016).

PTS das sub-bacias de $4^{\mathrm{a}}$ ordem

Somando as sub-bacias de $4^{\mathrm{a}}$ ordem hierárquica dos Rios São Domingos, São Vicente e São Mateus, há um total de 37sub-bacias, alcançando uma área de $872,03 \mathrm{~km}^{2}$. As sub-bacias identificadas como muito alto Potencial de Transferência de Sedimentos ocupam uma área de $6 \%, 24 \%$ apresentaram potencial alto, $43 \%$ apresentaram potencial médio e $27 \%$ das sub-bacias apresentaram potencial muito baixo.

A bacia do Rio São Domingos se destacou por apresentar duas subbacias com potencial de transferência muito alto, tal situação se deu devido à grande extensão dessas sub-bacias, à forma de relevo associado, ao tipo 
da formação rochosa e ao gradiente fluvial. A densidade de drenagem, que associa o comprimento de todos os canais com a área é também um dos principais fatores que determina o comportamento do canal fluvial, nesse caso, forte capacidade de transferir os sedimentos além da ocorrência junto à escarpa da Serra Geral de Goiás.

A Tabela 3 a seguir mostra a quantidade de sub-bacias e sua área correspondente para as três bacias hidrográficas da área de estudo quanto ao Potencial de Transferência de Sedimentos.

Tabela 3 - Quantidade de sub-bacias e área $\left(\mathrm{em} \mathrm{km}^{2}\right)$ quanto ao PTS, $4^{\mathrm{a}}$ ordem

\begin{tabular}{ccccccc}
\hline & Muito Alto & Alto & Médio & Baixo & Muito Baixo & Total \\
\hline Bacias & Quant./Área & Quant./Área & Quant./Área & Quant./Área & Quant./Área & Quant./Área \\
\hline S. Domingos & $2 / 235,45$ & $3 / 22,05$ & $10 / 107,30$ & $6 / 86,43$ & 0 & $21 / 451,24$ \\
\hline São Vicente & 0 & $2 / 123,65$ & $3 / 79,49$ & 0 & 0 & $5 / 203,14$ \\
\hline São Mateus & 0 & $4 / 42,29$ & $3 / 109,49$ & $4 / 73,87$ & 0 & $11 / 225,65$ \\
\hline & & & & Total & $37 / 872,03$ \\
\hline
\end{tabular}

Fonte: Elaborada pelos autores (2016).

De forma geral, as sub-bacias de $4^{\mathrm{a}}$ ordem hierárquica possuem maior capacidade em transportar os sedimentos, apresentando assim a possibilidade reduzida de depósito das partículas. 
PTS das Bacias dos Rios São Domingos, São Vicente e São Mateus, $4^{\circ}$ ordem

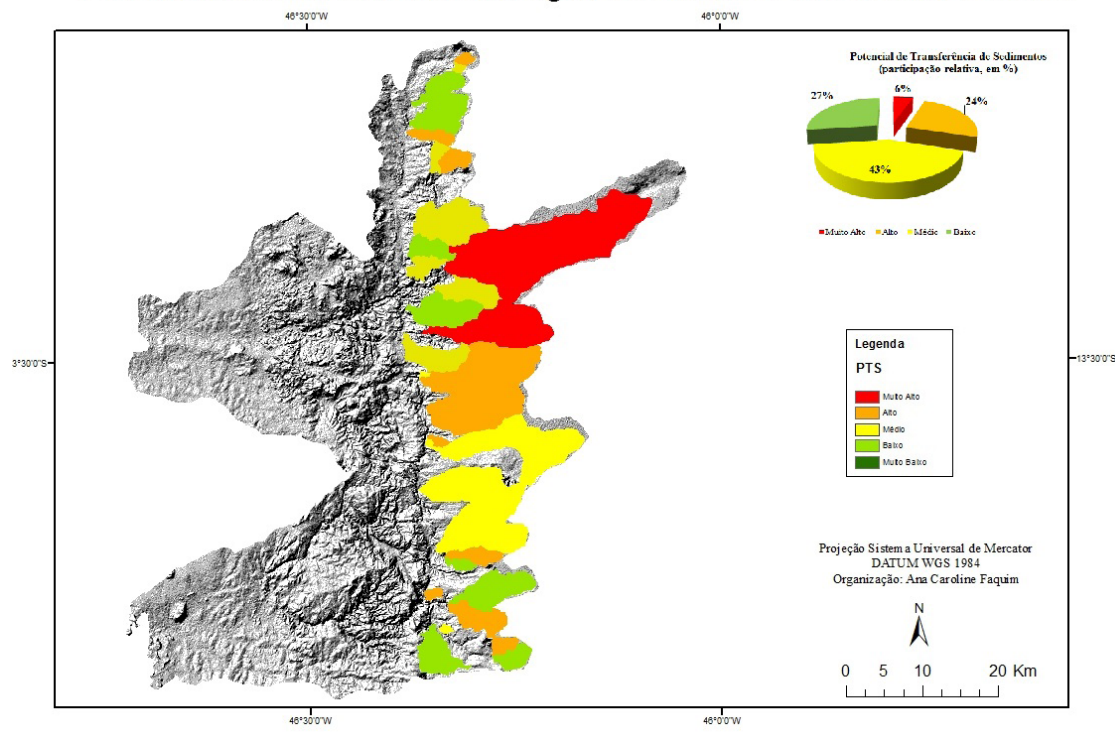

Figura 5 - PTS das Bacias dos Rios São Domingos, São Vicente e São Mateus, 4a ordem Fonte: SIEG (2016).

Comparação entre as diferentes ordens

A Figura 6 faz uma comparação entre as ordens hierárquicas analisadas. Foram identificas em toda a área de estudo 17 sub-bacias com muito alto potencial de transferência, 95 com alto PTS, 395 sub-bacias com médio potencial de transferência e 464 e 123, baixo e muito baixo PTS, respectivamente. 
PTS das sub-bacias por ordem em cada Bacia Hidrográfica

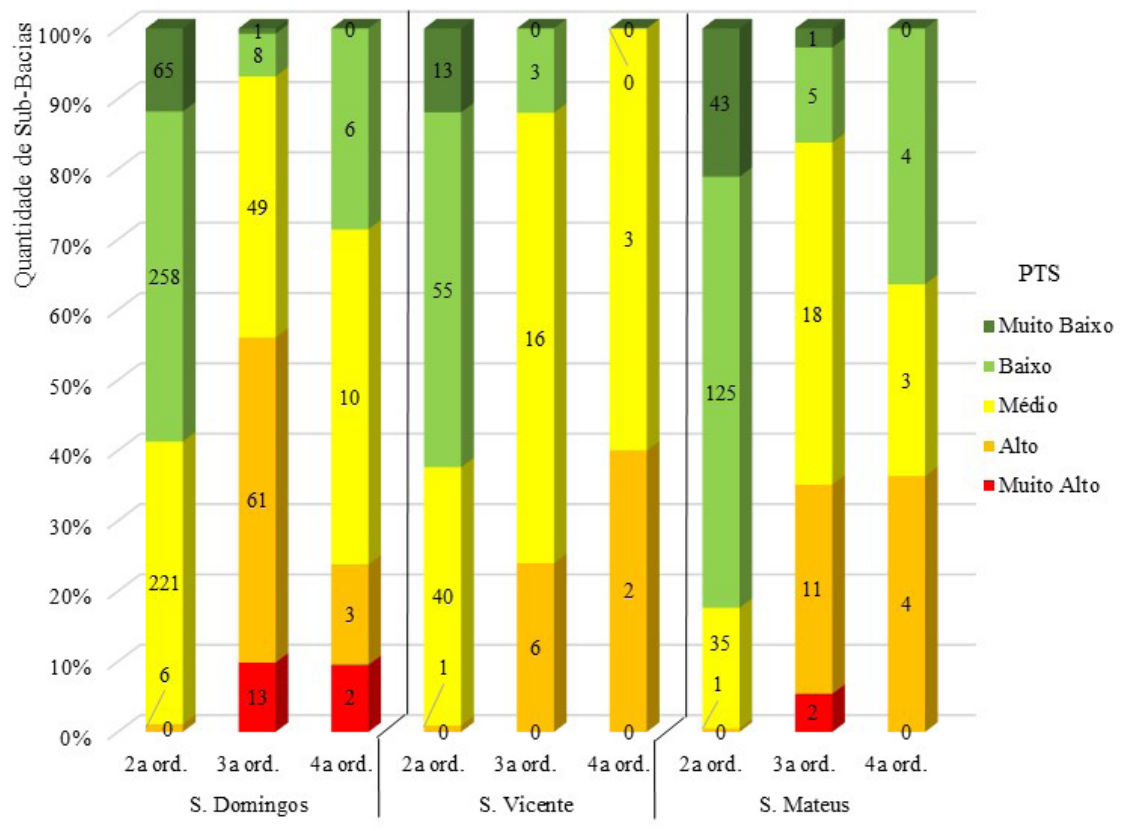

Figura 6 - Comparação de Potencial de Transferência de Sedimentos por sub-bacias entre as ordens hierárquicas em cada bacia hidrográfica

Fonte: Elaborada pelos autores (2016).

A comparação dos valores de PTS entre todas as ordens (Figura 6) indica que as sub-bacias de $3^{\mathrm{a}}$ ordem hierárquica apresentaram potenciais com tendência mais elevadas em relação às outras ordens. Por outro lado, as sub-bacias de $2^{\mathrm{a}}$ ordem apresentaram uma tendência para potenciais mais moderados.

Comparando as bacias hidrográficas (Figura 6), pode-se considerar que o PTS varia de moderado a baixo para as três bacias hidrográficas (São Domingos, São Vicente e São Mateus). Porém, nota-se que a do Rio São Domingos possui maior quantidade de sub-bacias com PTS muito alto, mas de forma geral tem capacidade moderada a baixa em transferir os sedimentos; tendência similar para a bacia do Rio São Mateus. 
PTS e as cavernas

Na área estudada, foram selecionadas sete cavernas que constituem sumidouros da porção superior das bacias dos rios S. Mateus, S. Vicente e S. Domingos. Três dessas cavernas estão na Bacia do S. Vicente e quatro na bacia do S. Mateus. A Figura 7 mostra a quantidade de sub-bacias com os respectivos PTS avaliados cuja rede de drenagem escoa para cada caverna identificada.

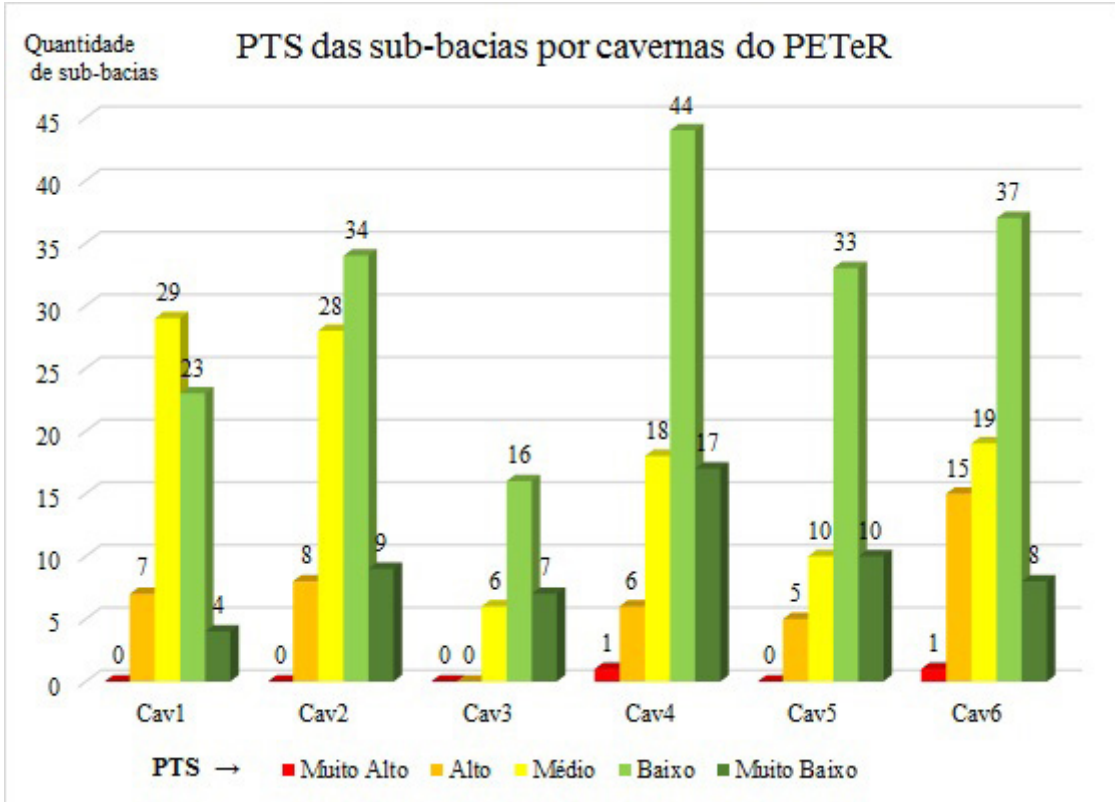

Figura 7 - Número de sub-bacias com PTS avaliado que drenam para as cavernas do PETeR Legenda: Cav1 - caverna do Rib. Angélica; Cav2 - caverna do Córrego Bezerra; Cav3 - caverna do Rio São Vicente; Cav4 - caverna do Rio São Mateus; Cav5 - caverna do Rio da Lapa (Terra Ronca); Cav6 - caverna do Ribeirão Palmeiras; Cav7 - caverna do Rio São Bernardo Fonte: Elaborada pelos autores (2016).

A caverna cuja rede de drenagem apresentou maior número de sub-bacias com PTS mais elevados foi a caverna do São Bernardo (Cav7), localizada na Bacia do Rio São Mateus, seguida da caverna Terra Ronca (Cav5) na mesma bacia (Figura 8). Posteriormente, em ordem decrescente 
de ocorrência de sub-bacias com PTS mais elevados, estão as cavernas do Bezerra (Cav2), do Angélica (Cav1), do Ribeirão Palmeiras (Cav6) e do São Mateus (Cav4).

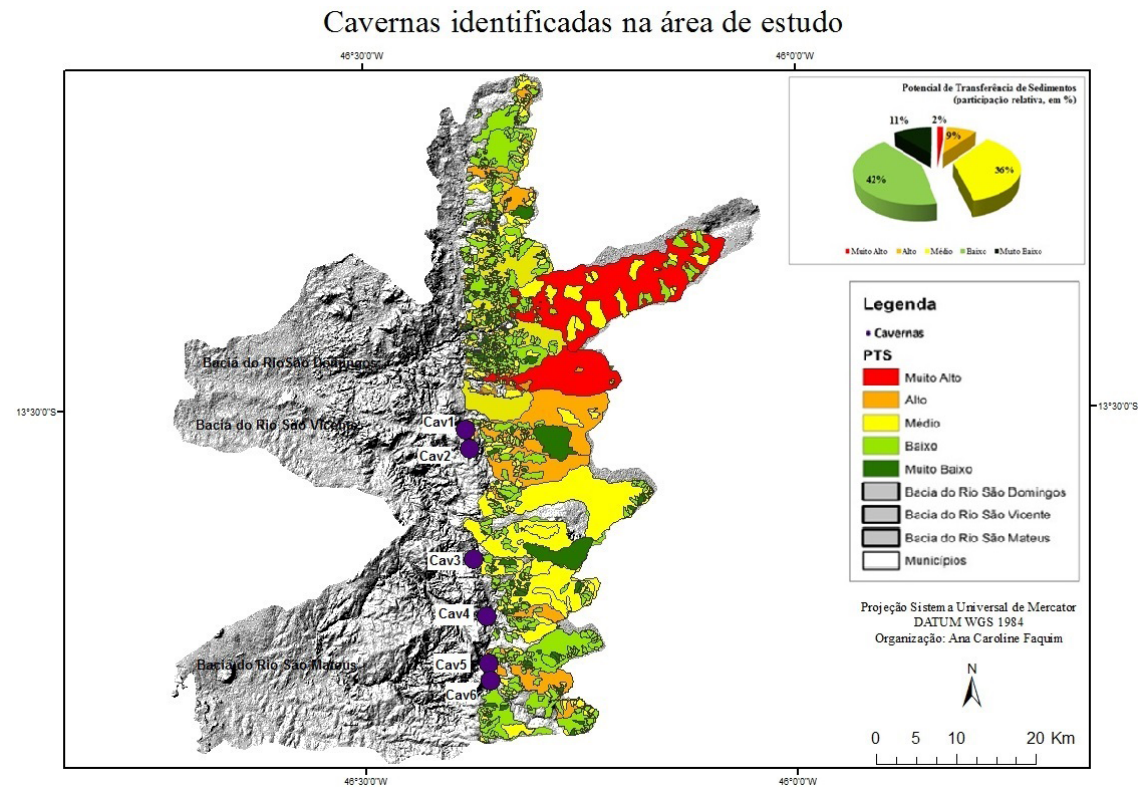

Figura 8 - Identificação das cavernas encontradas na área de estudo

Legenda: Cav1 - caverna do Rib. Angélica; Cav2 - caverna do Córrego Bezerra; Cav3 - caverna do Rio São Vicente; Cav4 - caverna do Rio São Mateus; Cav5 - caverna do Rio da Lapa (Terra Ronca); Cav6 - caverna do Ribeirão Palmeiras; Cav7 - caverna do Rio São Bernardo Fonte: SIEG (2016).

\section{Conclusão}

A porção superior das bacias hidrográficas dos rios S. Domingos, S. Vicente e S. Mateus apresentou Potencial de Transferência de Sedimentos (PTS) predominantemente moderado, seja por área relativa ou quantidade de sub-bacias contribuintes avaliadas. Esses potenciais sugerem que as redes de drenagem das sub-bacias possuem capacidade moderada para lançar sua carga sedimentar nas cavernas do Parque Estadual Terra Ronca. 
Em particular, as sub-bacias de $2^{\mathrm{a}}$ ordem hierárquica apresentaram em sua maior abrangência PTS baixos, ou seja, possuem deficiência relativa para transportar sedimentos. Porém, entre as sub-bacias de $3^{\text {a }}$ ordem, verificou-se a ocorrência maior de PTS mais elevados, destacando a bacia de São Domingos, localizada a norte da área de estudo; seguida pela bacia do São Matheus. Entre as sub-bacias de $4^{\mathrm{a}}$ ordem hierárquica, predominaram a ocorrência de PTS moderados a elevados, destacando novamente as bacias do S. Domingos e S. Mateus.

Esses resultados sugerem que mesmo estando próximas às cabeceiras nas escarpas da Serra Geral de Goiás, as sub-bacias de $2^{\mathrm{a}}$ ordem perdem capacidade de transporte quanto sua rede de drenagem atravessa os patamares aplainados embutidos no sopé da mesma serra. À medida que a rede de drenagem se aproxima dos terrenos cárticos, aumentam a ordem hierárquica, a densidade hidrográfica e o gradiente fluvial, indicando maior dissecação do relevo, elevando o potencial de transporte de sedimentos.

Entre as cavernas selecionadas neste estudo, a caverna do São Bernardo (Cav7) apresenta maior potencial em aporte de sedimentos, por constituir exutório da rede de drenagem com maior quantidade de sub-bacias com PTS mais elevados. No mesmo sentido, entre as demais cavernas em ordem decrescente de potencial de aporte de sedimentos, estão as cavernas Terra Ronca (Cav5), do Bezerra (Cav2), do Angélica (Cav1), do Ribeirão Palmeiras (Cav6) e do São Mateus (Cav4), respectivamente.

Ressalta-se que a maior parte da bacia do Rio São Mateus está fora da área de proteção integral do PETeR e contém a caverna do São Bernardo (Cav6) com o maior número de sub-bacias com PTS elevado. Desse modo, deve ser dada atenção prioritária ao uso, ocupação e manejo agropecuário desta bacia e da borda oeste dos chapadões da Bahia, junto à Serra Geral de Goiás.

Os resultados deste trabalho demonstram a capacidade potencial de transporte de sedimentos da rede de drenagem da área de estudo. Além das propriedades da rede de drenagem, a transferência efetiva de sedimentos depende das características naturais das bacias hidrográficas (solo, relevo etc.) e do uso e ocupação (remanescentes de vegetação, manejo, situação fundiária etc.). Desse modo, recomenda-se a ampliação dos estudos das bacias hidrográficas da área de estudo, voltados à análise integrada dos fatores e variáveis em questão, bem como o monitoramento da carga sedimentar injetada no sistema cárstico do PETeR. 


\section{Agradecimentos}

Agradecemos ao CNPq, pelo apoio financeiro ao projeto de pesquisa (Edital Universal MCTI-CNPq n. 14/2014; processo n. 461869/2014-4; vigência: 19/11/2014 a 31/11/2017) e à Universidade Federal de Goiás (UFG), pela concessão de bolsa do Programa Institucional de Iniciação Científica, os quais permitiram a realização deste trabalho. Também agradecemos à Gerência de Compensação Ambiental e Áreas Protegidas da Secretaria do Meio Ambiente, Recursos Hídricos, Infraestrutura, Cidades e Assuntos Metropolitanos do Estado de Goiás, pela autorização para as pesquisas no interior do Parque Estadual Terra Ronca.

\section{Referências}

BARRELLA, W. et al. As relações entre as matas ciliares os rios e os peixes. In: RODRIGUES, R. R.; LEITÃO FILHO; H. F. (Ed.). Matas ciliares: conservação e recuperação. 2. ed. São Paulo: Editora da Universidade de São Paulo, 2001.

BRASIL. Ministério das Minas e Energia. Projeto radambrasil: levantamento de recursos naturais, Folha SD 23 Brasília. Rio de Janeiro, 1982. v. 29. (6 mapas: geologia, geomorfologia, pedologia, vegetação, uso potencial da terra, avaliação do relevo).

CHRISTOFOLETTI, A. Geomorfologia. 2. ed. São Paulo: Edgard Blücher, 1980.

CPRM. Companhia de Pesquisa de Recursos Minerais. Projeto Rede Integrada de Monitoramento das Águas Subterrâneas: relatório diagnóstico Sistema Aquífero Urucuia Bacia Sedimentar Sanfranciscana. Belo Horizonte: CPRM - Serviço Geológico do Brasil, 2012. (Volume 10).

LATRUBESSE, E. M.; CARVALHO T. M. Geomorfologia do Estado de Goiás e Distrito Federal. Goiânia: Superintendência de Geologia e Mineração do Est. de Goiás, 2006. (Série Geologia e Mineração, n. 2).

LAUREANO, F. V. et al. Two million of river and cave aggradation in NE Brazil: implications for speleogenesis and landscape evolution. Geomorphology, v. 273, p. 63-77, 2016.

MATEUCCI, M. B.; SOARES FILHO, J. N.; NASCIMENTO, E. P. Mapa e roteiro ecoturístico do complexo de cavernas do Parque Estadual Terra Ronca - PETeR. In: INTERNATIONAL CONGRESS OF SPELEOLOGY, 13. Brasília, 2001. Anais... Brasília: UIS, SBE, 2001. p. 689-694.

MELIANI, P. F. Mapeamento da rede hidrográfica e análise dos parâmetros da densidade de drenagem aplicados ao estudo ambiental: o caso da Bacia do Rio Jeribucassu, Itacaré, Bahia. Geografia, Rio Claro, v. 31, n. 1, p. 119-136, jan./abr. 2006.

STRAHLER, A. N. Hypsometric (area-altitude) analysis of erosional topography. The Geological Society of America Bulletin, v. 63, p. 1117-1142, 1952. 
ZANCOPÉ, M. H. C.; BAYER, M. Proposta metodológica para avaliar o potencial de transferência de sedimentos de bacias hidrográficas a partir de índices morfométricos. In: SIMPÓSIO NACIONAL DE GEOMORFOLOGIA, 9, Rio de Janeiro, 2012, Anais....Rio de Janeiro: UFRJ/UGB, 2012. p. 1-3.

; GONÇALVES, P. E.; BAYER, M. Potencial de transferência de sedimentos e suscetibilidade a assoreamentos da rede hidrográfica do alto Rio Araguaia. Boletim Goiano de Geografia, Goiânia, v. 35, n. 1, p. 115-152, jan./abr. 2015.

; MOMOLI, R. S.; BAYER, M. Movimentos de massa nas nascentes do Rio $\bar{S} \overline{\tilde{a}} \bar{o}$ Vicente, Parque Estadual "Terra Ronca". Goiânia: LABOGEF, 2013. (Estudo técnico - Ofício SUCON; Secretaria do Meio Ambiente e Recursos Hídricos do Estado de Goiás).

Ana Caroline da Silva Faquim - é graduada em Ciências Ambientais, tem experiência na área de Geociências, atuando principalmente nos seguintes temas: Geomorfologia, Geomorfologia Fluvial e Geoprocessamento.

Márcio Henrique de Campos Zancopé - Possui Graduação em Geografia pela Universidade de São Paulo, licenciatura em Geografia pela Universidade de São Paulo, Mestrado em Geografia pela Universidade Estadual Paulista Júlio de Mesquita Filho e Doutorado em Geografia pela Universidade Estadual de Campinas. Atualmente é docente na Universidade Federal de Goiás.

Luis Felipe Soares Cherem - possui graduação em Geografia pela Universidade Federal de Minas Gerais, Mestrado em Análise e Modelagem de Sistemas Ambientais pela Universidade Federal de Minas Gerais e Doutorado em Evolução Crustal e Recursos Naturais pela Universidade Federal de Ouro Preto. Atualmente é conselheiro da União da Geomorfologia Brasileira e docente da Universidade Federal de Goiás.

\section{Contribuições dos autores}

Todos os autores ofereceram substanciais contribuições científicas e intelectuais ao estudo. As tarefas de concepção e design do estudo, preparação e redação do manuscrito, bem como, revisão crítica foram desenvolvidas em grupo. A autora Ana Caroline da Silva Faquim ficou responsável pelo desenvolvimento teórico-conceitual e pela aquisição e processamento de dados e análise; o segundo autor, Márcio Henrique de Campos Zancopé, pelo desenvolvimento teórico-conceitual, interpretação e análise de dados; e o terceiro, Luis Felipe Soares Cherem, pela interpretação e análise dos dados e tradução. 